\title{
The Analysis of the Factors of English Translation Strategy
}

\author{
Du juan ${ }^{1 \mathrm{a}}$,Weidong $\mathrm{Li}^{2 \mathrm{~b}}$,Xing $\mathrm{Li}^{1{ }^{\mathrm{c}}}$ \\ ${ }^{1}$ LongDong University ,QingYang City,Gansu 745000,China; \\ ${ }^{2}$ Gansu Province Rural Credit Union, Xifeng Union, 745000,China; \\ a786001120@QQ.com, b231901140@QQ.com, 'Tleebj@189.cn
}

Keywords: Translation; Factor analysis Characteristics; Strategies

\begin{abstract}
The research on English translation is systematic. With the change of the world economy, more and more Chinese and English are used in economy, as well as in a variety of scientific fields, and are cross-linked in large areas, so the strategy of English translation become increasingly important. On the basis of Chinese, the paper will analyze translation program, translation plan, translation scheme, translation module and translation framework through English translation strategy. It is discovered that it is helpful for the translators to do translation practice and disseminate in translation teaching by improving experience module, translation mode, translation strategy and method.
\end{abstract}

\section{Introduction}

Translation study is the unification of systemic research of macro, meso and micro strategy. Macro core theory should be transmitted from the meso-strategy, and micro-skills play a role at the operational level under the guidance of the meso- strategy. Translation strategy is the core parts of the translation study. Macro and micro translation study have been developed to a flourished level for decades, while a more spacious research room is found in the study of meso translation strategy. The paper discusses the motivation, factors and features of translation strategy. The term-Translation Strategy was introduced in translation study of China in the middle of 1990s, the same time with the introduction of foreignization. (Domestication has already been in translation theory of China.) The translation method which is related to translation strategy has been discussed so much in the traditional translation theory of China. In Chinese translation theory, there are two meaning in translation method, the first refers to the method which solves the specific problems in the process of translation (it is equivalent to translation technique), the second are the overall vision and approach which are used by the translator to convey the original content and form, such as literal translation, free translation and so on, and it is functionally comparable to translation strategy. There are many people both at home and abroad use this way to make a distinction between translation strategy and translation method, they think foreignization and domestication represented by translation strategy are at cultural level and pay more attention to culture, while literal translation and free translation represented by translation method are in text dimension, and text is emphasized. Such distinction is only the theoretical assumption, which makes little sense to translation study and translation practice.

\section{Literature review}

Translation strategy refers to the ideas, approaches, ways and procedures in the process of translation. Ideas and some macroscopic theory are caused from the same strain or are inspired by translation experience, approach is the feasible way to achieve the goal, way is the specific means to reach the target, and procedure is the priority of achieving the aim. These four aspects are complementary and mutually influential. From the prospective of translation study, translation strategy is the only way of macro theory connecting with translation practice throughout the translation process, and it can be inferred from macro theory, as well as derived from translation experience and techniques. Venuti 
(1998) defined translation strategy as strategies involve the basic task of choosing the foreign text to be translated and developing a method to translate it. Chesterman thought translation strategy therefore is to be seen as an act of translation, it should be viewed in the context of a broader action theory. From the historical, cultural, political and textual view, the culture school put forward many translation strategies which are adaptable to its translation theory and value system.

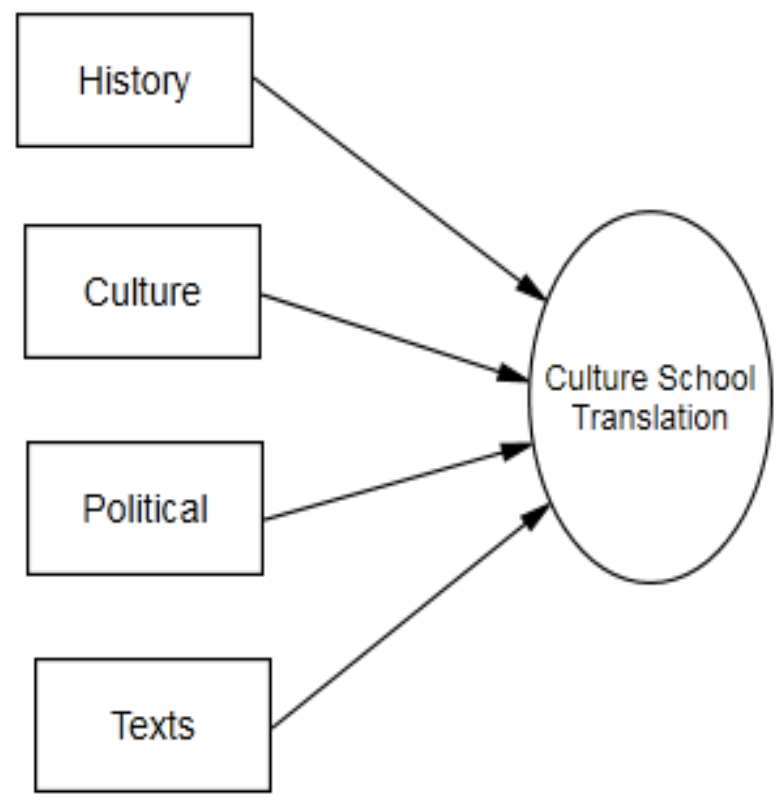

Fig. 1

While linguistic school proposed literal translation, free translation, transliteration, literal translation plus annotation, compensation, four-step model and so on.

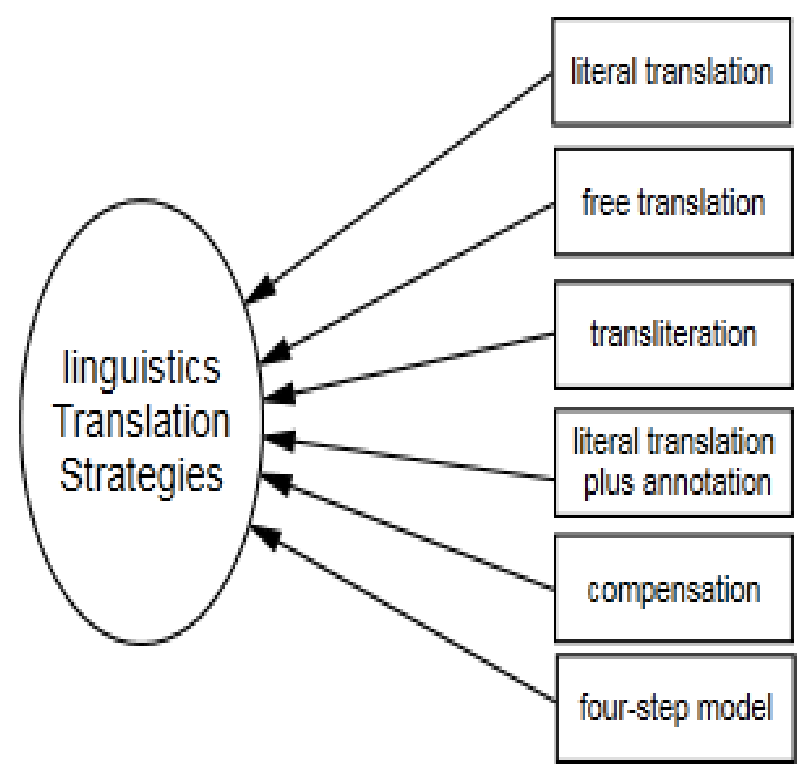

Fig. 2

\section{Elements of translation strategy}

Any translation strategy has three elements: the theory of factor, goal direction and technology. The theory of factor 


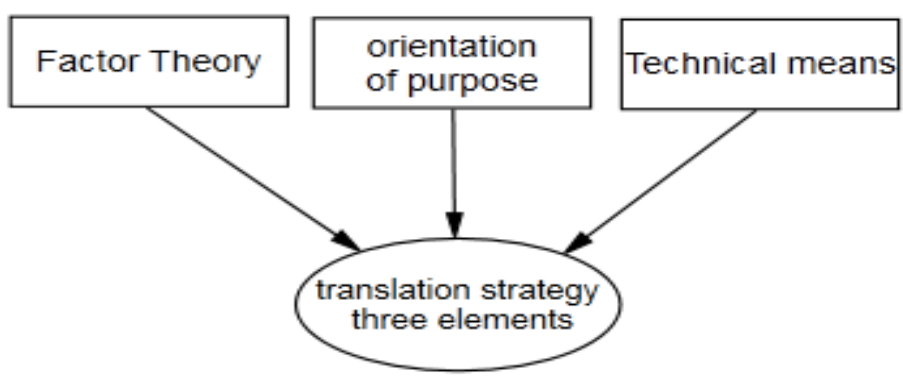

Fig. 3

All the theories of contemporary self- contained applied translation include the translation strategies. In turn, different translation strategies have their own theories. In 1960s, Nida proposed dynamic equivalence, which defined as "in terms of the degree to which the receptors of the message in the receptor language respond to it in substantially the same manner as the receptors in the source language" (Nida 1969:24). In order to achieve dynamic equivalence, Nida raised four-step model including analysis, transfer, restructuring and testing, and the model is originated from the theory. Traditional translation theory containing free translation, literal translation and transliteration should be faithful to the original. Under the guidance of the translation theory of the modern linguistic school, these strategies have been developed further and adopted in the theory of functional translation and communicative translation.

Goal direction

The translation strategy posed by Chesterman is described in the theoretical context of translation norms; it highlights purpose-related orientation and regards problem-centered skopos as the highest standards. Thus, the translator may choose some translation strategy or translation method to achieve translation purpose, at the same time, the translation itself becomes one of translation purposes in skopos. Culture school advocates foreignization whose strategic goal is to stress source culture, in other words, the translation should express something that is different from target culture, such as language forms, folk customs, cultural tradition and so on. The strategy adapted by a translator has something to do with the relevant social context. Translation strategy is the decision that a translator makes in the tensional relationship among language, history and social culture in his time. A variety of translation purposes of every initiator in translation are hidden behind such decision. And what's more, the purposes of a translator are so multiple that various translation strategies are adapted.

Technology

The technology of translation strategy is derived from the upper theory or deduced from translation practice and techniques. The four-step model proposed by Nida refers to analysis, transfer, restructuring and testing.

\section{Features of translation strategy}

In the unification of systemic research of macro, meso and micro of the translation study, the study of translation strategy is dominated; it is not only guided by macro translation theory, but also tested by micro-techniques. Comparing with macro-theory, translation strategy is more practical, because it is placed in the middle level of translation theory system, which is closer to the level of translation practice. With the development of macro translation theory and the accumulation of micro skills, it becomes very feasible. Translation strategy can be deduced form macro theory, as well as categorized and conceptualized by the synthesis and induction of micro skills, so such strategy is replicable and transferable, and it can be used as the important part and means of translation teaching. 
Table 1

\begin{tabular}{|l|l|l|l|}
\hline \multicolumn{4}{|c|}{ Characteristics of translation strategies } \\
\hline Cohesive & Practicality & Openness & Replicability \\
\hline
\end{tabular}

\section{Conclusion}

The paper discusses the meso research of translation strategy with philosophical methodology of one dividing into three, getting away from the mindset of binary thinking. In this methodology, the meso research is dominated and adjusted by macro theory, it bridges with micro theory and play a guiding role in the study of micro skills and translation practice. The purpose of translation strategy is to build a bridge of macro theory to translation practice. It turns out that self-contained theory of applied translation often deduces translation strategy or translation mode in accordance with its theoretical principles. On the other hand, partial and decentralized translation experience is intensified, conceptualized and categorized by induction, summarization and integration, and is promoted to be experience module, translation mode, translation strategy and method with more universal significance, (All these are the characteristics of the translation strategy of meso study.) which is useful for a translator to practice translation and teach. Because of the development of macro theory and enriching activity of translation, translation strategy is developed and enriched and abundant, which requires the further and extended study on macro theory of translation and translation practice.

\section{References}

[1] Appiah K A Thick Translation 1993(04)

[2] Baker M Routledge Encyclopedia of Translation Studies 2004

[3] Bassnett S Translation Studies (Third Edition) 2004

[4] Chesterman A Memes of Translation 1997

[5] Lefevere A Translation,Rewriting and the Manipulation of Literary Fame 1992

[6] Lefevere A Translation/History/Culture: A Sourcebook 1992

[7] Nida Eugene; Charles Taber The Theory and Practice of Translation 2004

[8] Li, Xing;Chen,Shieh-Liang;Liu,ChengHsiung,Research on radio frequency identification influence factors of enterprises,IEEE Workshop on Electronics, Computer and Applications, IWECA 2014,Ottawa, Canada,May 8- 9, 2014,pp.740-742 .dio: 10.1109/IWECA.2014.6845728

[9] Nord C Translating as a Purposeful Activity: Functionalist Approaches Explained 2001

[10] PACTE Building a Translation Competence Model 2003

[11] PACTE Investigating Translation Competence: Conceptual and Methodological Issues 2005(02)

[12] Venuti L The Translator's Invisibility: A History of Translation 1995

[13] Venuti L The Scandals of Translation: Toward an Ethics of Difference 1998

[14] Wilss W The Science of Translation: Problems and Methods 2001 